\title{
Lomagundi-Jatuli carbon isotope excursion - isotopic shift happens
}

A. LEPLAND ${ }^{1,2}$, K. BAKAKAS ${ }^{3}$, M. MOUSSAVOU ${ }^{3}$, T.

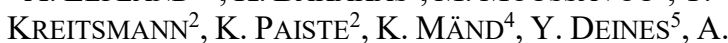
ROMASHKIN $^{5}$, A. PRAVE ${ }^{6}$ AND K. KIRSIMÄE ${ }^{2}$

${ }^{1}$ Geological Survey of Norway, 7491 Trondheim, Norway

${ }^{2}$ Tartu University, 50411 Tartu, Estonia

${ }^{3}$ Universite des Sciences et Techniques de Masuku, 943 Franceville, Gabon

${ }^{4}$ University of Alberta, Edmonton, AB T6G 2E3, Canada

${ }^{5}$ Karelian Research Centre, 185610 Petrozavodsk, Russia

${ }^{6}$ St Andrews University, KY169AL St Andrews, Scotland

Accumulation of isotopically heavy carbonates $\left(\delta^{13} \mathrm{C}\right.$ $10 \pm 5 \%$ o) at 2.3-2.0 Ga, known as the Lomagundi-Jatuli Event (LJE), reflects an apparent disturbance of the global carbon cycle after the Great Oxidation Event. This disturbance has been traditionally explained through enhanced biomass accumulation shifting the pool of global oxidized carbon, including oceanic DIC and sedimentary carbonates, towards ${ }^{13} \mathrm{C}$ enrichment. However, only minor organic-rich successions coeval with the LJE have been found, leaving the carbonate record and high $\delta^{13} \mathrm{C}$ variability unbalanced, and the LJE as an enduring enigma.

New isotope results integrated with sedimentologic observations from LJE successions in the Francevillian Basin, Gabon and Onega Basin, NW Russia, show a clear facies dependence on carbonate $\delta^{13} \mathrm{C}$ values: distinctly positive values characterize shallow-water platform carbonates whereas deep-water deposits exhibit near zero $\delta^{13} \mathrm{C}$ values. Systematic, facies-controlled isotopic shifts occur across a few tens-of-meters of stratigraphic thickness as observed in drill cores from both basins. Such isotopic shifts towards zero values upwards in both successions have been previously considered to track the termination of the global LJE. Our new findings challenge this concept and, instead, show that accumulation of isotopically heavy LJE carbonates was confined to shallow water settings whereas the bulk oceanic and global carbon cycle may have experienced limited if any isotopic disturbance at that time. 